\title{
Investigation of Behçet's Disease and Recurrent Aphthous Stomatitis Frequency: The Highest Prevalence in Turkey
}

\author{
Yalçın Baş $^{1}$, Havva Yıldız Seçkin ${ }^{1}$, Göknur Kalkan ${ }^{1}$, Zennure Takc1 ${ }^{1}$, Yalçın Önder ${ }^{2}$, Rıza Çıtı1², \\ Selim Demir ${ }^{3}$, Şafak Şahin ${ }^{4}$
}

\begin{abstract}
${ }^{1}$ Department of Dermatology, Gaziosmanpaşa University School of Medicine, Tokat, Turkey
${ }^{2}$ Department of Public Health, Gaziosmanpaşa University School of Medicine, Tokat, Turkey

${ }^{3}$ Department of Ophthalmology, Gaziosmanpaşa University School of Medicine, Tokat, Turkey

${ }^{4}$ Department of Internal Medicine, Gaziosmanpaşa University School of Medicine, Tokat, Turkey
\end{abstract}

Background: The Recurrent Aphthous Stomatitis (RAS) is the most frequently observed painful pathology of the oral mucosa in the society. It appears mostly in idiopathic form; however, it may also be related with systemic diseases like Behçet's Disease (BD).

Aims: Determining the prevalence of RAS and BD in the Northern Anatolian Region, which is one of the important routes on the Antique Silk Road.

Study Design: Cross-sectional study.

Methods: Overall, 85 separate exemplification groups were formed to reflect the population density, and the demographic data of the region they represent. In the first stage, the individuals, who were selected in random order, were invited to a Family Physician Unit at a certain date and time. The dermatological examinations of the volunteering individuals were performed by only 3 dermatology specialists. In the second stage, those individuals who had symptoms of BD were invited to our hospital, and the Pathergy Test and eye examinations were performed.
Results: The annual prevalence of RAS was determined as $10.84 \%$. The annual prevalence was determined to be higher in women than in men $(p=0.000)$. It was observed that the prevalence was at the peak level in the $3^{\text {rd }}$ decade, and then decreased proportionally in the following decades $(\mathrm{p}=0.000)$. It was also observed that the aphtha recurrence decreased in the following decades $(\mathrm{p}=0.048)$. The Behçet's prevalence was found to be $0.60 \%$. The prevalence in women was found to be higher than in men $(0.86 \%$ female, $0.14 \%$ male; $p=0.022$ ).

Conclusion: While the RAS prevalence ratio was at an average value when compared with the other societies; the $\mathrm{BD}$ prevalence was found as the highest ratio in the world according to the literature.

Keywords: Behçet's disease, prevalence, recurrent aphthous stomatitis
The oral cavity consists of many anatomic bodies that have different histologic structures and functions like the tongue, gingiva, cheek, palate, etc. These anatomic structures have many pathologic lesions together with many variations that are observed frequently in society. Recurrent Aphthous Stomatitis (RAS) is the most frequently observed painful pathology of the oral mucosa in the society. Clinically, it is a superficial ulcer, single or many in number, surrounded by an erythematous halo, in round or oval form, with smooth edges, and yel- low or grey background (1). It appears mostly in idiopathic form; however, it may also be related with systemic diseases like Behçet's Disease (BD). Behçet's Disease is defined as a chronic inflammatory disease involving repetitive oral and genital aphthous ulcers, skin lesions, uveitis, arthritis, thrombophlebitis and arterial aneurysm. Although BD is observed worldwide, it is more frequently observed in countries on the Antique Silk Road, which starts from Japan and stretches to Middle Eastern and Mediterranean countries (2).

This study was presented at the 22 ${ }^{\text {nd }}$ Prof. Dr. A. Lütfü Tat Symposium, 18-22 November 2015, Ankara, Turkey. 
With this study, the prevalence of RAS and BD in Tokat city, which is one of the important routes on the Antique Silk Road, has been determined. Also, the relations of these diseases with the demographic data, use of tobacco and alcohol, chronic diseases, body mass index, urban/rural regions and some nutritional/hematological factors have been analyzed.

\section{MATERIALS AND METHODS}

Ethical approval was obtained from the Institutional Review Board (Approval Number: 83116987-278, 14-KAEK129). All participants were volunteers and provided written informed consent.

\section{Selection of the exemplification}

The study was conducted in the city of Tokat, which reflects the population characteristics of the Northern Anatolian Region. According to the data of the Turkish Statistical Institute for 2013, the population of Tokat is 598,708, with 59\% of the population living in urban areas, and $41 \%$ living in rural areas. As the target population of the study, the adult population of Tokat, who are 20 years old or above, have been selected (412.653).

Since all of the citizens of the Republic of Turkey are registered in the Family Physician System, this formed the basis of this study. Overall, 85 (50\%) of the 170 Family Physician Units in the city of Tokat were included in the study, and 85 exemplification groups (52 urban, 33 rural) were formed. The groups were formed in such a structure that could reflect the population pyramid and demographic characteristics of the area in which they were located. The volunteers were chosen randomly from individuals who were aged 20 or above and who were being followed by the Family Physician Units.

\section{Study design}

In the first stage, the individuals who were randomly chosen were invited to the Family Physician Units on a certain day and at a certain time. The examinations of the volunteer individuals were performed only by 3 dermatology specialists in the field in the Family Physician Units. The blood samples for the planned tests were taken in the field and were transported using proper methods.

In the second stage, patients who had symptoms of BD were invited to our hospital and underwent the pathergy test and eye examinations. The blood samples taken were studied in the laboratory of our hospital.

The hemogram, serum iron, Total Serum Iron Binding Capacity (TIBC), ferritin, vitamin B12 and folic acid values were measured. The hemoglobin levels $<13 \mathrm{mg} / \mathrm{dL}$ for men, and $<12 \mathrm{mg} / \mathrm{dL}$ for women were determined as anemia. Those from patients with anemia which were $<50 \mathrm{ng} / \mathrm{mL}$ were interpreted as iron deficiency anemia, and those $>50 \mathrm{ng} / \mathrm{mL}$ were interpreted as chronic disease anemia.

The patients who described at least 3 classic attacks in one year were diagnosed with RAS. During the diagnosis, the criteria recommended by Natah et al. (3) were taken as the basis. The following exclusion criteria were applied: Autoimmune bullous dermatosis, oral malignancies, oral lichen planus, systemic lupus erythematosus, erythema multiforme, Steven Johnson Syndrome, toxic epidermal necrolysis, celiac disease, Crohn's disease, ulcerative colitis, human immunodeficiency virus (HIV) infection, hand-foot-and-mouth disease and recurrent herpes labialis. The complaints of the patients were classified as continuous, several times a month, several times in two months, several times in three months, several times in six months, and at least three times a year. In the diagnosis of $\mathrm{BD}$, the criteria of the International Work Group were used (4). In addition, demographic factors, medical history, family history, anthropometry, alcoholic beverage consumption and tobacco use of the individuals were recorded. Body Mass Index (BMI) was calculated as weight $(\mathrm{kg}) / \mathrm{height}\left(\mathrm{m}^{2}\right)$. The volunteers were evaluated in six age groups: 20-29, 30-39, 4049, 50-59, 60-69, and 70 and above.

\section{Statistical analysis}

Percentage and average \pm standard deviation (minimummaximum) were used in definitive statistics; the Chi-square and Fisher's Chi-square Test were used in the comparison of the data obtained with counting, and the Student $t$ Test was used for the comparison of data obtained by measurements.

The normal proper for the distribution analyses (Kolmogorov Smirnov test) were used for the data groups obtained by the measurements. In comparing the data groups that did not fit the normal distribution, the Mann-Whitney U test was used. The estimation of the analysis results of the data obtained by counting were shown as relative risk (odds ratioOR) and 95\% Confidence Interval (CI).

The statistical meaningfulness level was accepted as $\mathrm{p}<0.05$. The data were evaluated by using the Statistical Package for the Social Sciences 18.0/Windows ${ }^{\circledR}$ (IBM SPSS Statistics; Armonk, NY, USA).

\section{RESULTS}

In total, 2428 individuals were interviewed and 2325 volunteers were included in the study (1290 women, 1035 men). The ages of the volunteers who participated in the study varied between 20 and 87 (average age $47.3 \pm 15.3$; women $46.6 \pm 15.3$, men $48 \pm 15.4)$. 


\section{RAS}

The annual prevalence of RAS was found to be $10.84 \%$ (n: 252) $(1084 / 10,000)(95 \%$ CI, 957-1210/10,000), and the point prevalence was $0.7 \%$ (n: 16 ). The annual prevalence in women was found to be higher than in men $(13.1 \%$ women, $8 \%$ men) $(\mathrm{p}=0.000)$. The point prevalence in women was $0.8 \%(\mathrm{n}$ : 11 ), and $0.5 \%$ (n: 5) in men. The aphtha frequency was classified as continuously repetitive in $7.5 \%$, several times a month in $42.9 \%$, several times in two months in $13.8 \%$, several times in three months in $13 \%$, several times in six months in $3.5 \%$, and at least 3 times in a year in $19.3 \%$. It was observed that the prevalence increased to the peak value in the 3rd decade, and then decreased proportionally in the following decades (Figure 1) $(\mathrm{p}=0.000)$. It was also observed that the aphtha recurrence decreased in the following decades $(\mathrm{p}=0.048)$.

\section{RAS}

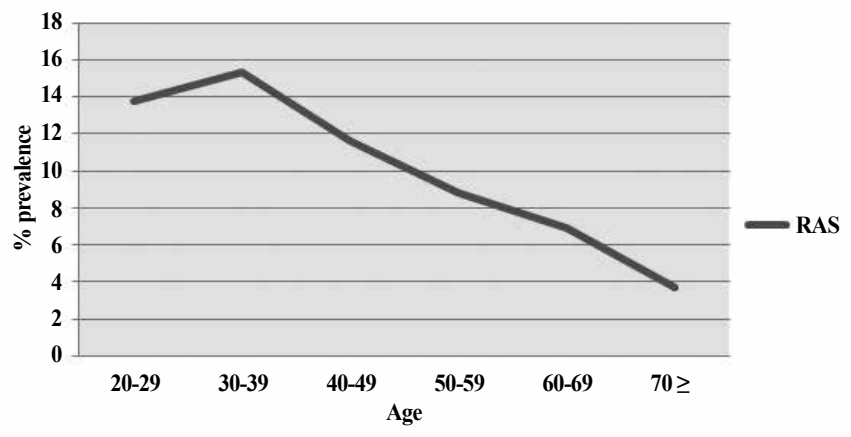

FIG. 1. The prevalence of recurrent aphthous stomatitis by age

When the professions are considered, a high prevalence was determined in students $(17.9 \%)$, and officers $(14.9 \%)$, while in farmers $(5.9 \%)$ and retired groups $(6.5 \%)$, a low prevalence was detected $(\mathrm{p}=0.001)$. The RAS prevalence values of those who lived in urban areas (10.8\%) and rural areas (10.9\%) were close to each other; however, the aphtha recurrence of those who lived in urban areas was found to be more acute $(\mathrm{p}=0.019)$.

In smokers, the prevalence was determined to be $4.5 \%$, in non-smokers it was determined as $13.2 \%$, and in those who used to smoke in the past it was determined to be $10.2 \%$ $(\mathrm{p}=0.000)$. Additionally, it was determined that the aphtha recurrence was lower in smokers ( $\mathrm{p}=0.041)$.

The average serum iron, ferritin, vitamin B12, folate, mean corpuscular volume (MCV) and hemoglobin tests were detected within the normal limits; when compared with the values of those who did not have RAS, no statistically significant difference was determined (Table 1). Only the Total Serum
TABLE 1. A comparison of the average value of the test results with the community

\begin{tabular}{lccc}
\hline & RAS & Society & $\mathrm{p}$ \\
\hline $\mathrm{Hgb}$ & 13.04 & 13.48 & $\mathrm{I}$ \\
$\mathrm{MCV}$ & 84.11 & 85.64 & $\mathrm{I}$ \\
$\mathrm{Fe}$ & 81.66 & 86.29 & $\mathrm{I}$ \\
$\mathrm{TIBC}$ & 385.38 & 373.00 & 0.020 \\
Ferritin & 60.53 & 75.79 & $\mathrm{I}$ \\
B12 & 330.86 & 326.01 & $\mathrm{I}$ \\
Folic acid & 7.69 & 7.67 & $\mathrm{I}$ \\
\hline Fe: & &
\end{tabular}

Fe: iron; I: insignificant; RAS: recurrent aphthous stomatitis; MCV: mean corpuscular volume; Hgb: hemoglobin; TIBC: total serum iron binding capacity

Iron Binding Capacity (TIBC) was within the normal limits; however, it was determined to be higher when compared with those who did not have RAS (RAS negative 373, RAS positive 385.38; reference interval 250-450 $\mu \mathrm{g} / \mathrm{dL})(\mathrm{p}=0.020)$.

\section{Behçet's disease}

The prevalence of Behçet's Disease was found to be $0.60 \%$ (n: 14) $(60 / 10,000)(95 \%$ CI, 29-92/10,000). Six of the 14 patients with Behçet's Disease received new diagnoses during the study. Other individuals had been formerly diagnosed with Behçet's Disease and followed by the relevant centers.

The prevalence in women was found to be higher than men ( $0.86 \%$ women, $0.14 \%$ men; $\mathrm{p}=0.022$ ). Overall, $100 \%$ of the patients had RAS, $71 \%$ had genital ulcers, $78 \%$ had pseudofolliculitis, $28 \%$ had erythema nodosum, $28 \%$ had eye involvement, $14 \%$ had arthritis and $57 \%$ had positive pathergy test (Table 2). No statistically significant results were determined in other demographic data of the patients, i.e. the use of tobacco and alcoholic beverages, BMI and chronic diseases.

\section{DISCUSSION}

\section{Recurrent aphthous stomatitis}

Oral ulcers are among the common complaints of the patients who apply to policlinics. It is estimated that the oral ulcer point prevalence in the whole world is $4 \%$ (5). RAS, on the other hand, is the most commonly observed oral mucosa disease among oral ulcer types. In addition, it is one of the most frequent painful lesions of the oral mucosa. The pain affects the life quality of the patients and cause problems in nutrition. It is said that RAS affects $20 \%$ of the society at any time (6). However, the prevalence of RAS has a wide range, 5-66\%, in studies conducted in different societies and age groups (7-9). 
TABLE 2. Result of epidemiological surveys of Behçet's disease conducted in Turkey

\begin{tabular}{|c|c|c|c|c|c|c|}
\hline & $\begin{array}{l}\text { Demirhindi } \\
\text { et al. (22) }\end{array}$ & $\begin{array}{l}\text { Azizlerli } \\
\text { et al. (24) }\end{array}$ & $\begin{array}{l}\text { Yurdakul } \\
\text { et al. (25) }\end{array}$ & $\begin{array}{c}\text { Idil } \\
\text { et al. (23) }\end{array}$ & $\begin{array}{c}\text { Cakir } \\
\text { et al. (26) }\end{array}$ & Current \\
\hline Sample size & 4940 & 23986 & 5121 & 17256 & 15280 & 2325 \\
\hline Number of patients & 4 & 101 & 19 & 16 & 3 & 14 \\
\hline Prevalence rate $(\mathrm{n} / 10,000)$ & 8 & 42 & 37 & 11 & 19.6 & 60 \\
\hline $95 \%$ CI (n/10,000) & $2-14$ & $34-51$ & $20-54$ & $4.4-13.5$ & $17-21$ & $29-92$ \\
\hline \multicolumn{7}{|l|}{ Manifestations (\%) } \\
\hline RAS & 100 & 100 & 100 & 100 & 100 & 100 \\
\hline Genital ulcers & 75 & 70.2 & 73.7 & 75 & 50 & 71 \\
\hline Pseudofollculitis & 75 & 39.6 & 94.7 & - & 50 & 78 \\
\hline Erythema nodosum & 50 & 36.6 & 42.1 & - & - & 28 \\
\hline Eye & 50 & 27.7 & 0 & 43.7 & - & 28 \\
\hline Arthritis & 25 & 28.7 & 47.4 & & - & 14 \\
\hline Positive pathergy & 33 & 69.3 & 33.3 & 81.2 & 100 & 57 \\
\hline
\end{tabular}

In this study, on the other hand, the annual prevalence of RAS has been found to be $10.84 \%$ (95\% CI, 957-1210/10,000), which means an average value when compared with other societies. These different results may be explained by the method used in the study, and the genetic inclination of the work group, demographic characteristics, and dietary habits.

Recurrent Aphthous Stomatitis is observed at high levels in young adults when compared with the elderly (10). In this study, the prevalence has been determined to be higher in young adults than in the elderly, which is in accordance with the literature (10). It was observed that the prevalence was at the peak level in the 3rd decade, and then decreased proportionally in the following decades $(\mathrm{p}=0.000)$. It was also observed that the aphtha recurrence decreased in the following decades $(p=0.048)$. However, it is not clear why this decrease happens. The tolerance which develops in time against the immunological mechanisms, which is suggested in the etiology, or the change in hormones with the furthering age, may be possible causes of the decrease observed in the prevalence. In addition, leading a more sedentary life as the age further increases, and thus a decrease in the stress factor may affect the prevalence.

The RAS prevalence has been found to be higher in women than in men in most of the studies conducted (10). In our study, the annual prevalence was determined to be higher in women than in men, which is in accordance with the literature $(13.1 \%$ women, $8 \%$ men; $\mathrm{p}=0.000$ ). Women are prone to stress and emotional situations that may affect their immune system. Additionally, the change in hormones during pregnancy and menstruation may also play a role (11). Moreover, women are more sensitive than men, and their pain threshold is lower.
Men, on the other hand, may be more careless than women in remembering lesions and caring for and being aware of them. Therefore, Rivera-Hidalgo et al. (10) suggested using the point prevalence of RAS instead of its annual prevalence, and determined that the annual prevalence of RAS was high, and inversely proportional, with the point prevalence being higher in men. In this study, although it is not statistically significant, the point prevalence of RAS was higher in women, which is in contrast to that reported by Rivera-Hidalgo et al. (10) $(0.8 \%$ women, $0.5 \%$ men). However, more comprehensive societybased studies must be conducted in order to obtain more reliable data on determining the point prevalence.

When RAS frequency in terms of professions are considered, high prevalence was determined in students $(17.9 \%)$, and officers $(14.9 \%)$; a low prevalence was determined in farmers $(5.9 \%)$ and retired groups $(6.5 \%)(p=0.001)$. This difference may be explained by the average ages of retired individuals, and those dealing with farming being higher. Additionally, it is known that those people who deal with stressful jobs are more prone to RAS. The mechanism of stress in this issue is not clear. However, it probably has its effects via multiple system changes like the production and activity of lymphocytes, and the production of cytokines and antibodies (12). Another possible mechanism is its ability to induce the para-functional habits, like biting the lips of the cheek and its forming predisposition due to trauma (1). The RAS prevalence of the people living in urban areas (10.8\%) and rural areas (10.9\%) were determined as being close to each other; however, the aphtha recurrence of those living in urban areas was found to be more significant $(p=0.019)$. This situation, again, is interrelated with the stress that is brought along with urban life. 
In RAS, there are different results about the plasma iron, vitamin $\mathrm{B} 12$ and folic acid levels $(3,13,14)$. In most studies, it was reported that the iron, folic acid and vitamin B12 deficiency were observed more often in patients with RAS $(3,13,14)$. However, in our study, in serum iron, ferritin, vitamin B12 and folic acid and hemogram tests of the patients with RAS, the average values were found to be within the normal limits; in comparisons of individuals who did not have RAS, no statistically significant results were obtained (Table 1). In the literature, there are in similar results to those reported by our study, but the cause of these different outcomes is not clear (15-17). It is known that the RAS prevalence is higher in women and the young than in men (10). Women are more prone to iron deficiency and anemia than men in society, and if these and other similar characteristics are not considered statistically, the incorrect results may be obtained. In addition, the various different results may be explained with the genetic characteristics and dietary habits of different societies $(3,14)$.

There is a significant decrease in RAS prevalence in the smoking population (1). In this study, the RAS prevalence in the smoking population has been found to be significantly lower, which is in accordance with the literature (Smokers $4.5 \%$, non-smokers $13.2 \%)(\mathrm{p}=0.000)$. In addition, it has been determined that the aphtha recurrence has been determined as being less in smokers $(p=0.041)$. The ability of cigarettes to increase mucosal keratinization and form a protective effect against traumas and microbial agents may be one of the possible mechanisms $(18,19)$. Another possible mechanism seems to involve the immunologic mechanisms that have a role in the development of RAS lesions. It is reported that the nicotine, which is one of the important active substances in tobacco, is the main agent responsible for a decrease in RAS (10). It was shown that there was a decrease in RAS attacks in studies where nicotine replacement treatment was conducted (20). Nicotine may affect the immunologic mechanisms indirectly by inducing glucocorticoid production over the hypothalamus-pituitary-adrenal pathway in the central nervous system, and decreasing the severity of the inflammation over the autonomic nervous system (10). In addition, it can also affect the immunologic mechanisms directly by decreasing the production of TNF- $\alpha$ and some interleukins over the nicotinic acetylcholine receptors on the macrophages (10).

\section{Behçet's disease}

The prevalence of BD shows variety among different geographic regions (21); in particular, the ratio in regions on the Antique Silk Road is much higher than that in Europe and America. The prevalence of $\mathrm{BD}$ has been determined as 2.1-
19.5/100,000 in Asian countries, as 1.5-15.9 in Southern European countries, and as 0.3-4.9 in Northern European Countries (21). The highest ratios in countries were found in the countries that were located on the Antique Silk Road like Turkey (19.6-420), Israel (15.2-120), Iran (16.7-68), Iraq (17) and Japan (7-13.5) (21). When the literature is considered, the highest $\mathrm{BD}$ prevalence ratios were determined in Turkey (19.6-420/100,000) (21). So far, five studies have been conducted regarding the epidemiology of $\mathrm{BD}$ in different regions of Turkey (Table 2) (22-26). However, this study is the first epidemiologic study conducted in our region, and the BD prevalence has been found to be at higher levels than those found in Turkey and in the world previously $(602 / 100,000$, 95\% CI 290-920).

Clinically, BD progresses with attacks and remission. Patients generally apply to health institutions when the clinical symptoms become severe. For this reason, in epidemiologic studies, the clinical findings of the disease are detected at less severe levels, when compared with the hospital-based studies (21). In this study, basically mucocutaneous involvement has been detected in the majority of the patients (Table 2).

In conclusion, RAS prevalence has been found at an average level compared with other societies. It has been detected in higher frequencies in women and young adults, which is in accordance with the literature. Meaningful differences in terms of profession, living area etc. have been observed, and this situation has mainly been related the stress factor.

Contrary to the studies conducted, no meaningful relation was detected between RAS and the vitamins/hematological factors.

Recurrent Aphthous Stomatitis prevalence in smokers have been determined as being clearly at lower levels. Due to the many known sources of harm from cigarettes, it is strictly not recommended in treatment. However, this situation may be used as a step in determining the RAS etiopathogenesis and treatment.

According to the literature, the BD prevalence has been determined as being at the highest level in the world. This may be related to the fact that the study was conducted in Tokat city, which is located on one of the important routes of the Antique Silk Road.

Ethics Committee Approval: Ethics committee approval was was received for this study from the Institutional Review Board (Approval Number: 83116987-278, 14-KAEK-129).

Informed Consent: Written informed consent was obtained from patients who participated in this study.

Peer-review: Externally peer-reviewed. 
Author contributions: Concept - Y.B., H.Y.S., G.K., Z.T.; Design - Y.B., H.Y.S., G.K., Z.T.; Supervision - Y.B., H.Y.S., G.K., Z.T.; Resource - Y.B., H.Y.S., G.K., Z.T.; Materials - Y.B., H.Y.S., G.K., Z.T.; Data Collection and/or Processing - Y.B., H.Y.S., G.K., Z.T., Y.Ö., R.Ç., S.D., Ş.Ş.; Analysis and/or Interpretation - Y.B., H.Y.S., G.K., Z.T., Y.Ö., R.Ç., S.D., Ş.Ş.; Literature Search - Y.B., H.Y.S., G.K., Z.T., Y.Ö., R.Ç., S.D., Ş.Ş.; Writing - Y.B.; Critical Reviews - Y.B., H.Y.S., G.K., Z.T., Y.Ö., R.Ç., S.D., Ş.Ş.

Conflict of Interest: No conflict of interest was declared by the authors.

Financial Disclosure: The authors declared that this study has received no financial support.

\section{REFERENCES}

1. Preeti L, Magesh K, Rajkumar K, Karthik R. Recurrent aphthous stomatitis. J Oral Maxillofac Pathol 2011;15:252-6. [Crossref]

2. Sakane T, Takeno M, Suzuki N, Inaba G. Behçet's disease. $N$ Engl J Med 1999;341:1284-91. [Crossref]

3. Natah SS, Konttinen YT, Enattah NS, Ashammakhi N, Sharkey KA, Häyrinen-Immonen R. Recurrent aphthous ulcers today: a review of the growing knowledge. Int J Oral Maxillofac Surg 2004;33:221-34. [Crossref]

4. International Study Group for Behçet's Disease. Criteria for diagnosis of Behçet's disease. Lancet 1990;335:1078-80.

5. Shulman JD, Beach MM, Rivera-Hidalgo F. The prevalence of oral mucosal lesions in U.S. adults: data from the Third National Health and Nutrition Examination Survey, 1988-1994. J Am Dent Assoc 2004;135:1279-86. [Crossref]

6. Patil S, Reddy SN, Maheshwari S, Khandelwal S, Shruthi D, Doni B. Prevalence of recurrent aphthous ulceration in the Indian Population. J Clin Exp Dent 2014;6:36-40. [Crossref]

7. Pongissawaranum W, Laohapand P. Epidemiologic study on recurrent aphthous stomatitis in a Thai dental patient population. Community Dent Oral Epidemiol 1991;19:52-3. [Crossref]

8. Porter SR, Scully C, Pedersen A. Recurrent aphthous stomatitis. Crit Rev Oral Biol Med 1998;9:306-21. [Crossref]

9. Davatchi F, Tehrani-Banihashemi A, Jamshidi AR, Chams-Davatchi $\mathrm{C}$, Gholami J, Moradi M, et al. The prevalence of oral aphthosis in a normal population in Iran: a WHO-ILAR COPCORD study. Arch Iran Med 2008;11:207-9.

10. Rivera-Hidalgo F, Shulman JD, Beach MM. The association of tobacco and other factors with recurrent aphthous stomatitis in an US adult population. Oral Dis 2004;10:335-45. [Crossref]

11. Zain RB. Oral recurrent aphthous ulcers/stomatitis: prevalence in Malaysia and an epidemiological update. J Oral Sci 2000;42:15-9. [Crossref]
12. Huling LB, Baccaglini L, Choquette L, Feinn RS, Lalla RV. Effect of stressful life events on the onset and duration of recurrent aphthous stomatitis. J Oral Pathol Med 2012;41:149-52. [Crossref]

13. Wray D, Ferguson MM, Mason DK, Hutcheon AW, Dagg JH. Recurrent aphthae: treatment with vitamin B12, folic acid and iron. Br Med J 1975;2:490-3. [Crossref]

14. Scully C, Porter S. Oral mucosal disease: Recurrent aphthous stomatitis. Br J Oral Maxillofac Surg 2008;46:198-206. [Crossref]

15. Aynali G, Ozkan M, Aynali A, Ceyhan B, Armağan H, Yarıktaş $\mathrm{M}$, et al. The evaluation of serum vitamin B12, folic acid and hemoglobin levels in patients with recurrent minor aphthous stomatitis. Kulak Burun Bogaz Ihtis Derg 2013;23:148-52. [Crossref]

16. Thongprasom K, Youngnak P, Aneksuk V. Hematologic abnormalities in recurrent oral ulceration. Southeast Asian J Trop Med Public Health 2002;33:872-7.

17. Olson JA, Feinberg I, Silverman S Jr, Abrams D, Greenspan JS. Serum vitamin B12, folate, and iron levels in recurrent aphthous ulceration. Oral Surg Oral Med Oral Pathol 1982;54:517-20. [Crossref]

18. Bookman R. Relief of Canker Sores on Resumption of Cigarette Smoking. Calif Med 1960;93:235-6.

19. Grady D, Ernster VL, Stillman L, Greenspan J. Smokeless tobacco use prevents aphthous stomatitis. Oral Surg Oral Med Oral Pathol 1992;74:463-5. [Crossref]

20. Scheid P, Bohadana A, Martinet Y. Nicotine patches for aphthous ulcers due to Behcet's syndrome. NEngl J Med 2000;343:18167. [Crossref]

21. Mahr A, Maldini C. Epidemiology of Behçet's disease. Rev Med Interne 2014;35:81-9. [Crossref]

22. Demirhindi O, Yazici H, Binyildiz P, Dayioglu N, Tuzun Y, Altac M, et al. The prevalence of Behcet's disease in Fener village (Silivri, Istanbul) and its sur-roundings. Cerrahpasa journal of med 1981;12:509-14.

23. Idil A, Gurler A, Boyvat A, Caliskan D, Ozdemir O, Isik A, et al. The prevalence of Behcet's disease above the age of 10 years. The results of a pilot study conducted at the Park Primary Health Care Center in Ankara, Turkey. Ophthalmic Epidemiol 2002;9:325-31. [Crossref]

24. Azizlerli G, Kose AA, Sarica R, Gul A, Tutkun IT, Kulaç M, et al. Prevalence of Behcet's disease in İstanbul, Turkey. Int $J$ Dermatol 2003;42:803-6. [Crossref]

25. Yurdakul S, Günaydın I, Tüzün Y, Tankurt N, Pazarli H, Ozyazgan $\mathrm{Y}$, et al. The prevalence of Behçet's syndrome in a rural area in northern Turkey. J Rheumatol 1988;15:820-2.

26. Cakir N, Pamuk ON, Dervis E, Imeryuz N, Uslu H, Benian O, et al. The prevalences of some rheumatic diseases in western Turkey: Havsa study. Rheumatol Int 2012;32:895-908. [Crossref] 